\title{
Flyback Converter with Quadratic Pre-Stage
}

\author{
FELIX A. HIMMELSTOSS ${ }^{1}$, KARL H. EDELMOSER ${ }^{2}$ \\ ${ }^{1}$ Power Electronics Department \\ University of Applied Science Technikum Wien \\ Hoechstaedtplatz 6, 1200 Wien \\ ${ }^{2}$ Institute of Energy Systems and Electrical Drives \\ University of Technology Vienna \\ Gusshausstraße 24-26, 1040 Wien \\ AUSTRIA
}

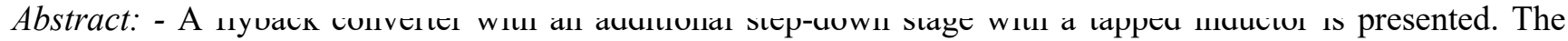
function of the converter is described and the voltage transformation rates for the continuous mode are derived. The dimensioning equations for the devices are given. The dynamic model is calculated and simulations are shown. The converter enables an isolated output and shows a wide range in the transformation rate. It is especially useful for small solar applications in addition to a micro-inverter.
\end{abstract}

Key-Words: - DC/DC converter, flyback converter, quadratic, modelling, simulation, dimensioning

Received: December 3, 2019. Revised: May 15, 2020. Accepted: June 2, 2020. Published: June 13, 2020

\section{Introduction}

The converter (Fig. 1) consists of a flyback stage with the active switch S1, the coupled inductors $\mathrm{N}_{21}$ and $\mathrm{N}_{22}$, a secondary diode $\mathrm{D}_{3}$ and an output capacitor $\mathrm{C}_{2}$, and a first stage built with two magnetically coupled windings $\mathrm{N}_{11}$ and $\mathrm{N}_{12}$ (built as a tapped inductor or as an autotransformer), a capacitor $\mathrm{C}_{1}$ and two diodes $\mathrm{D}_{1}, \mathrm{D}_{2}$. This first stage brings an additional quadratic step-down factor into the voltage transformation rate of the flyback converter. This converter is especially useful for high step-down ratios and when isolation of the output is necessary. For the whole area of power electronics and for the flyback converter cf. [1-3], the basic text for converters with a quadratic term in the voltage transformation rate is [4]. An overview of four converters with a low-side switch and tapped inductors at the output side is presented in [5]. Similar circuits, but with a tapped inductor at the input side, are treated in [6]. Further concepts and hints for the control can be found in [7-12]. The flyback part of the converter and the coupled windings in the pre-stage enable the designer to adapt input and output voltages with a large difference. The potential separation is another advantage of this converter, especially for security reasons. The converter has two modes in the continuous mode: mode $\mathrm{M} 1 \mathrm{~S}$ and $\mathrm{D}_{1}$, and mode M2 $\mathrm{D}_{2}$ and $\mathrm{D}_{3}$ are conducting. As with all flyback-based converters, the power range is up to about $200 \mathrm{~W}$, because the energy which has to be transferred must by stored first in the magnetic elements.

\section{Basic function in the steady-state case}

For the description of the circuit in the steady-state case we assume ideal devices (that means no losses, and infinitesimally small switching times), continuous operation, and the capacitors are so large that the voltage across them does not change during one switching period (if we allow a significant voltage ripple, especially across $C_{1}$, one has to use the mean value). When the active switch is on (also diode $\mathrm{D}_{1}$ is on during this mode), the input voltage $\mathrm{U}_{1}$ minus the voltage across $\mathrm{C}_{1}$ is across the series connection of the coupled windings $\mathrm{N}_{11}$ and $\mathrm{N}_{12}$.

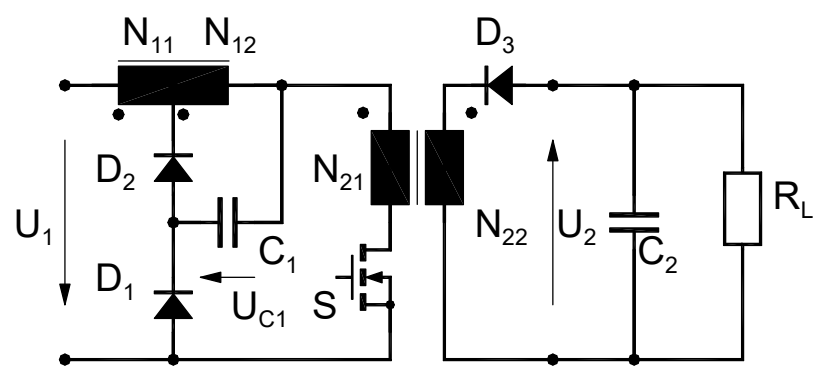

Fig. 1. Quadratic flyback converter with pre-stage.

The voltage across the separate windings can be calculated by the transformer law. The voltage across the capacitor is impressed on the primary winding $\mathrm{N}_{21}$ of the flyback transformer. When the switch $\mathrm{S}$ is turned off, the current through the coupled winding can only flow in the winding $\mathrm{N}_{12}$ and commutates to $\mathrm{D}_{2}$. The magnetic flux has to be steady, therefore also the ampere windings have to 
be steady and the current through $\mathrm{N}_{12}$ must spring to a higher value so that the ampere windings do not change. The flyback transformer is demagnetized with the help of the secondary winding $\mathrm{N}_{22}$. Therefore, one can write for the voltage-time balance for the winding $\mathrm{N}_{12}$ and for the winding $\mathrm{N}_{22}$

$$
\begin{aligned}
& \frac{N_{12}}{N_{11}+N_{12}}\left(U_{1}-U_{C}\right) d=U_{C}(1-d), \\
& U_{C 1} \frac{N_{22}}{N_{21}} d=U_{2}(1-d)
\end{aligned}
$$

respectively. So one can write for the voltage across $\mathrm{C}_{1}$ and the output voltage $\mathrm{U}_{2}$ in dependence on the input voltage and with the duty cycle $d$ (the turn-on time of the active switch divided by the switching period) for the ideal converter in continuous inductor current mode

$$
\begin{gathered}
U_{C}=\frac{N_{12}}{N_{11}+N_{12}-N_{11} d} d U_{1} \\
U_{2}=\frac{d^{2}}{1-d} \frac{N_{12}}{N_{11}+N_{12}-N_{11} d} \frac{N_{22}}{N_{21}} U_{1} .
\end{gathered}
$$

Choosing a winding ratio of one to one for $\mathrm{N}_{11}$ to $\mathrm{N}_{12}$ simplifies to

$$
U_{2}=\frac{d^{2}}{(1-d)} \frac{1}{(2-d)} \frac{N_{22}}{N_{21}} U_{1} .
$$

Fig. 2 shows the voltage transformation rate for different winding ratios of the flyback stage. The coupled windings are chosen as bifilar windings with the winding ratio one to one. One can see that the converter has also a large voltage transformation factor when the winding ratio $\mathrm{N}_{22} / \mathrm{N}_{21}$ is high. When a small winding ratio is used, the converter is especially useful for step-down applications.

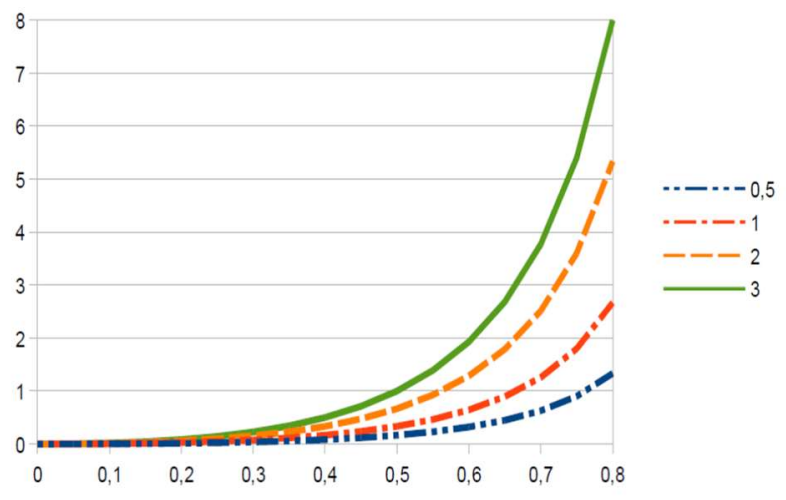

Fig. 2. Voltage transformation rate $M$ (y-axis) in dependence upon the duty cycle $\mathrm{D}$ (x-axis) for different winding ratios $\mathrm{N}_{22} / \mathrm{N}_{21}$ and equal winding $\mathrm{N}_{11}$ and $\mathrm{N}_{12}$.

\section{Voltage stress of the semiconductors}

The normalized stress of the semiconductors can be calculated with the help of Kirchhoff's voltage law (KVL). It is not helpful to replace the duty cycle by the output voltage, because these formulae would get very confusing. Therefore, we calculate them only in accordance to the duty cycle. From the input and the output voltage range for a given application the necessary duty cycle to achieve the highest stress has to be calculated and inserted into (5a, 6, 7, 8 ), respectively. This leads to maximum values. It is evident that the used devices must be chosen with a security factor of 30 to $100 \%$ depending on the application.

To get a clearer comprehension of how to get the voltage stress across the semiconductors, the voltages across the active switch $\mathrm{S}$ and the three passive switches $D_{1}$ to $D_{3}$ are depicted in the figures Fig. 3 to Fig. 6.

Fig. 3 shows the voltage across the active switch. The voltage stress can be calculated during mode M2 according to

$$
U_{S}=U_{C 1} \frac{N_{11}+N_{12}}{N_{12}}+U_{1}+\frac{N_{21}}{N_{22}} U_{2} .
$$

Substituting the voltages across $\mathrm{C}_{1}$ and the output voltage $\mathrm{U}_{2}$ lead to the normalized voltage across the active switch

$$
\frac{U_{S}}{U_{1}}=\frac{d^{2} N_{11}-2 d N_{11}+N_{11}+N_{12}}{\left(N_{11}+N_{12}-d N_{11}\right)(1-d)} .
$$

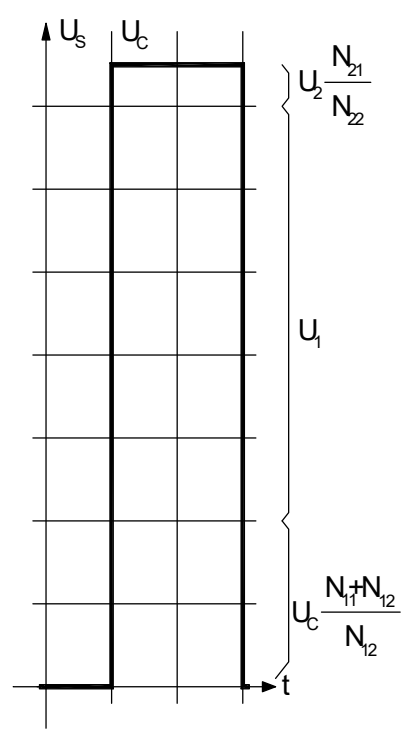

Fig. 3. Voltage across the active switch S.

For the voltage across $\mathrm{D}_{1}$ one gets

$$
\frac{U_{D 1}}{U_{1}}=-\frac{N_{11}+N_{12}}{\left(N_{11}+N_{12}-d N_{11}\right)}
$$


Fig. 4 shows the voltage across the diode $\mathrm{D}_{1}$.

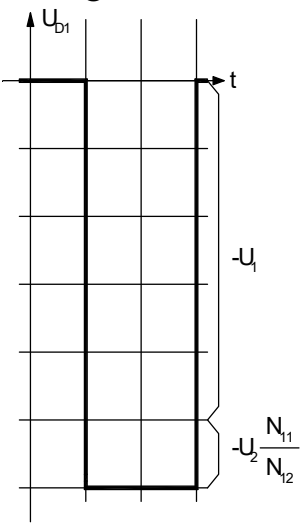

Fig. 4. Voltage across $D_{1}$.

For $\mathrm{D}_{2}$ (Fig. 5) one gets

$$
U_{D 2}=-U_{1}+\left(U_{1}-U_{C 1}\right) \frac{N_{11}}{N_{11}+N_{12}} .
$$

This leads to

$$
\begin{aligned}
& \frac{U_{D 1}}{U_{1}}=-\frac{N_{12}}{\left(N_{11}+N_{12}-d N_{11}\right)} \\
& \underbrace{U_{02}}_{1} \quad\left[\begin{array}{l}
t \\
U_{1} \\
\left(U_{1}-U_{C}\right) \frac{N_{11}}{N_{11}+N_{12}}
\end{array}\right.
\end{aligned}
$$

Fig. 5 Voltage across $\mathrm{D}_{2}$

For the necessary normalized reverse voltage of $\mathrm{D}_{3}$ (Fig. 6)

$$
\frac{U_{D 3}}{U_{1}}=-\frac{N_{22}}{N_{21}} \frac{d N_{12}}{\left(N_{11}+N_{12}-d N_{11}\right)(1-d)} .
$$

For the necessary normalized reverse voltage of $D_{3}$ for an equal number of windings of the coupled coils.

$$
\frac{U_{D 3}}{U_{1}}=-\frac{N_{22}}{N_{21}} \frac{d}{(2-d)(1-d)}
$$

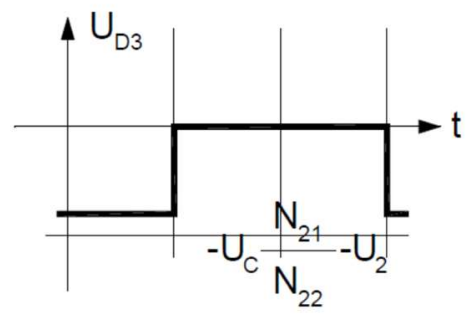

Fig. 6 Voltage across $\mathrm{D}_{3}$.

\section{Connection between the currents}

To get an overview of the current stress of the elements, one has to inspect the currents through the capacitors. It is easy to construct the mean values of the currents. For the output capacitor one gets a graph which is shown in Fig. 7.

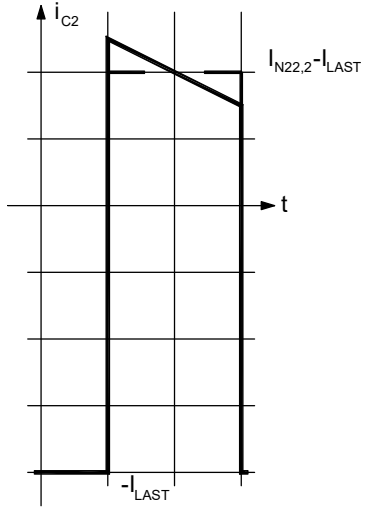

Fig. 7. Current through the output capacitor in steady state.

The current through the capacitor must be zero in the mean. Starting with the load current one can draw the current through the output capacitor (Fig. 7), (e.g. for a duty cycle of one third).

Due to the charge balance one can write

$$
I_{\text {Load }} d=\left(\bar{I}_{D 3,2}-I_{\text {Load }}\right)(1-d) .
$$

$\bar{I}_{D 3,2}$ is the mean value of the current through $\mathrm{D}_{3}$ referred to the duration of mode M2 and is equal to the mean value of the current during M2 through the secondary winding of the flyback transformer.

During mode M2 the current through the secondary winding is therefore (Fig. 8)

$$
\bar{I}_{N 22,2}=\frac{1}{1-d} I_{\text {Load }}
$$

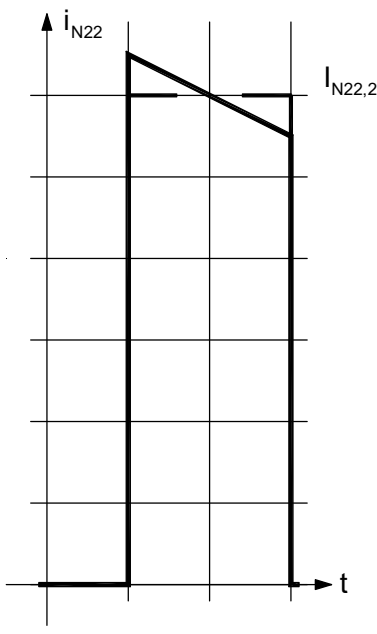

Fig. 8. Current through the secondary winding. 
The current through the primary winding is zero in M2. The ampere-windings must be the same in the core. Therefore, one gets for the mean value of the current through $\mathrm{N}_{21}$ in the first mode M1

$$
\bar{I}_{N 21,1}=\bar{I}_{N 22,2} \frac{N_{22}}{N_{21}}=\frac{N_{22}}{N_{21}} \frac{I_{\text {Load }}}{1-d}
$$

Fig. 9 shows a sketch of the current through the primary winding with a winding ratio of $\mathrm{N}_{21}: \mathrm{N}_{22}=2: 1$. The current during M1 in N21 is half of the current through $\mathrm{N}_{22}$ during M2. With the given winding ratio, we can draw the current through the primary winding, which has to be at the end of mode M1 half of the current as at the beginning of mode M2 in the secondary winding (the current linkage must be steady and the winding ratio is $\mathrm{N}_{21}: \mathrm{N}_{22}=2: 1$ ).

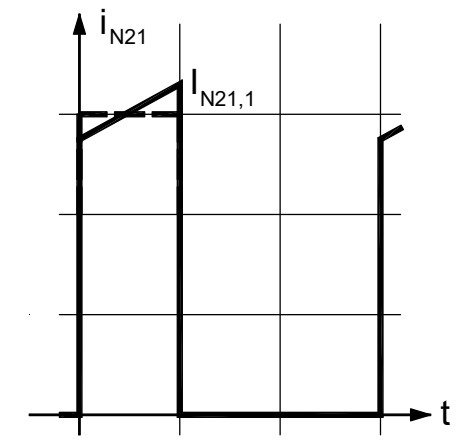

Fig. 9. Current through the primary winding.

Now one can construct the current through the capacitor $\mathrm{C}_{1}$. The mean value of the inductor current and the mean value of the current through the primary winding related to M1 are used.

Now the charge balance of the first capacitor can be written according

$$
\left(\bar{I}_{N 21,1}-\bar{I}_{N 12,1}\right) d=\bar{I}_{N 12,2}(1-d) .
$$

Now one is able to calculate the current through the second winding of the coupled coils during mode M2

$$
\bar{I}_{N 12,2}=\frac{N_{11}+N_{22}}{N_{11}+N_{12}-d N_{11}} \cdot \frac{N_{22}}{N_{21}} \frac{d}{1-d} I_{\text {Load }} .
$$

The ampere-windings must be the same at the end of M1 and the beginning of mode two

$$
\bar{I}_{N 11,1}\left(N_{11}+N_{12}\right)=\bar{I}_{N 12,2} N_{12} .
$$

This leads to

$$
\bar{I}_{N 12,1}=\frac{N_{12}}{N_{11}+N_{12}-d N_{11}} \cdot \frac{N_{22}}{N_{21}} \frac{d}{1-d} I_{\text {Load }} .
$$

The mean value of the input current is therefore

$$
\bar{I}_{1}=\frac{N_{12}}{N_{11}+N_{12}-d N_{11}} \cdot \frac{N_{22}}{N_{21}} \frac{d^{2}}{1-d} I_{\text {Load }} .
$$

\section{Dynamic model of the converter}

\subsection{Calculating the state equations}

The state variables which form the state vector are

$$
\underline{x}=\left(\phi_{1}, \phi_{2}, u_{C 1}, u_{C 2}\right) .
$$

The fluxes $\phi_{1}, \phi_{2}$ are the state variables for the coupled coils, because the flux in the magnetic elements has to be steady. The currents in the windings are not steady and can spring. This causes overvoltages due to the unavoidable stray inductances. To reduce these overvoltages, snubber networks or overvoltage limiters have to be used. One can use simple RCD snubbers or networks, which recuperate the energy which is stored in the stray inductance into the input or into the output side of the converter to increase the efficiency [ 1 , 2]. The flux is proportional to the current, the proportional factor is called inductance. One has to use the induction law

$$
u=\frac{d}{d t} \psi=N \frac{d}{d t} \phi .
$$

When the flux $\psi$ is changing, a voltage is induced. For a concentrated winding with the number of turns $\mathrm{N}$, one can use the flux per winding $\phi$. Therefore, one can write during stage M1 for the induction law

$$
\frac{d \psi_{1}}{d t}=N_{12} \frac{d \phi_{1}}{d t}=\frac{N_{12}}{N_{11}+N_{12}}\left(u_{1}-u_{C 1}\right) .
$$

The inductance can be calculated with the $\mathrm{A}_{\mathrm{L}}$-factor and the square of the number of windings according to

$\left(N_{12}+N_{12}\right) \phi_{1}=\psi_{1}=L_{1+2} i=A_{L}\left(N_{12}+N_{12}\right)^{2} \cdot i$.

For the magnetic core of the flyback transformer one can write

$$
\frac{d \psi_{2}}{d t}=N_{21} \frac{d \phi_{2}}{d t}=u_{C 1} .
$$

The connection between flux and the causing current

$$
N_{21} \phi_{2}=\psi_{2}=A_{L} N_{21}^{2} \cdot i
$$

enables us to write for the derivatives of the voltages across $C_{1}$

$$
\frac{d u_{C 1}}{d t}=\frac{1}{C_{1}}\left(\frac{\phi_{1}}{A_{L}\left(N_{11}+N_{12}\right)}-\frac{\phi_{2}}{A_{L} N_{21}}\right) .
$$


The capacitor $\mathrm{C}_{2}$ has to supply the load

$$
\frac{d u_{C 2}}{d t}=-\frac{u_{C 2}}{C_{2} R} \text {. }
$$

The state-space description for mode M1 can be written according to

$$
\begin{aligned}
\frac{d}{d t}\left(\begin{array}{c}
\phi_{1} \\
\phi_{2} \\
u_{C 1} \\
u_{C 2}
\end{array}\right) & {\left[\begin{array}{cccc}
0 & 0 & -\frac{1}{N_{11}+N_{12}} & 0 \\
0 & 0 & \frac{1}{N_{21}} & 0 \\
\frac{1}{A_{L}\left(N_{11}+N_{12}\right) C_{1}} & -\frac{1}{A_{L} N_{21} C_{1}} & 0 & 0 \\
0 & 0 & 0 & -\frac{1}{C_{2} R}
\end{array}\right] } \\
& \left(\begin{array}{c}
\phi_{1} \\
\phi_{2} \\
u_{C 1} \\
u_{C 2}
\end{array}\right)+\left[\begin{array}{c}
1 \\
N_{11}+N_{12} \\
0 \\
0 \\
0
\end{array}\right]\left(u_{1}\right)
\end{aligned}
$$

During mode $M 2$ the diodes $\mathrm{D}_{2}$ and $\mathrm{D}_{3}$ are conducting, the derivatives of the fluxes are therefore

$$
\begin{aligned}
& N_{12} \frac{d \phi_{1}}{d t}=\frac{d \psi_{1}}{d t}=-u_{C 1} \\
& N_{22} \frac{d \phi_{2}}{d t}=\frac{d \psi_{2}}{d t}=-u_{C 2} .
\end{aligned}
$$

With the help of the flux linkages

$$
\begin{aligned}
& N_{12} \phi_{1}=\psi_{1}=A_{L} N_{12}^{2} \cdot i \\
& N_{22} \phi_{2}=\psi_{2}=A_{L} N_{22}^{2} \cdot i
\end{aligned}
$$

one can write for the state equations of the capacitors

$$
\begin{aligned}
& \frac{d u_{C 1}}{d t}=\frac{\phi_{1} /\left(A_{L} N_{12}\right)}{C_{1}} \\
& \frac{d u_{C 2}}{d t}=\frac{\phi_{2} /\left(A_{L} N_{22}\right)-u_{C 2} / R}{C_{2}} .
\end{aligned}
$$

Summarized in a state-space description one gets for mode M2

$$
\frac{d}{d t}\left(\begin{array}{c}
\phi_{1} \\
\phi_{2} \\
u_{C 1} \\
u_{C 2}
\end{array}\right)=\left[\begin{array}{cccc}
0 & 0 & -\frac{1}{N_{12}} & 0 \\
0 & 0 & 0 & -\frac{1}{N_{22}} \\
\frac{1}{A_{L} N_{12} C_{1}} & 0 & 0 & 0 \\
0 & \frac{1}{A_{L} N_{22} C_{2}} & 0 & -\frac{1}{C_{2} R}
\end{array}\right]\left(\begin{array}{c}
\phi_{1} \\
\phi_{2} \\
u_{C 1} \\
u_{C 2}
\end{array}\right)
$$

\subsection{Large signal model}

Combining the equations for both modes by averaging leads to the nonlinear model (state space averaging)

$$
\frac{d}{d t}\left(\begin{array}{c}
\phi_{1} \\
\phi_{2} \\
u_{C 1} \\
u_{C 2}
\end{array}\right)=
$$

$\left[\begin{array}{cccc}0 & 0 & -\frac{N_{11}+N_{12}-d N_{11}}{\left(N_{11}+N_{12}\right) N_{12}} & 0 \\ 0 & 0 & \frac{d}{N_{21}} & \frac{d-1}{N_{22}} \\ \frac{N_{11}+N_{12}-d N_{11}}{A_{L}\left(N_{11}+N_{12}\right) N_{12} C_{1}} & -\frac{d}{A_{L} N_{21} C_{1}} & 0 & 0 \\ 0 & \frac{1-d}{A_{L} N_{22} C_{2}} & 0 & -\frac{1}{C_{2} R}\end{array}\right]$ $\left(\begin{array}{c}\phi_{1} \\ \phi_{2} \\ u_{C 1} \\ u_{C 2}\end{array}\right)+\left[\begin{array}{c}d \\ N_{11}+N_{12} \\ 0 \\ 0 \\ 0\end{array}\right]\left(u_{1}\right)$

This model can be linearized and that leads to a small-signal model from which the transfer functions can be derivated. Furthermore, one gets also the connection between the working point values.

\subsection{Small signal model}

All variables are written as the sum of the working point value marked by a capital letter with a 0 in the index and a perturbation term of this variable, marked by a small letter with a roof on top. This results in a small signal model around the operating point

$$
\frac{d}{d t}\left(\begin{array}{l}
\hat{\phi}_{1} \\
\hat{\phi}_{2} \\
\hat{u}_{C 1} \\
\hat{u}_{C 2}
\end{array}\right)=A\left(\begin{array}{l}
\hat{\phi}_{1} \\
\hat{\phi}_{2} \\
\hat{u}_{C 1} \\
\hat{u}_{C 2}
\end{array}\right)+B\left(\begin{array}{c}
\hat{u}_{1} \\
\hat{d}
\end{array}\right)
$$

With the abbreviations for the matrixes

$$
A=\left[\begin{array}{cccc}
0 & 0 & -\frac{N_{11}+N_{12}-D_{0} N_{11}}{\left(N_{11}+N_{12}\right) N_{12}} & 0 \\
0 & 0 & \frac{D_{0}}{N_{21}} & \frac{D_{0}-1}{N_{22}} \\
\frac{N_{11}+N_{12}-D_{0} N_{11}}{A_{L}\left(N_{11}+N_{12}\right) N_{12} C_{1}} & -\frac{D_{0}}{A_{L} N_{21} C_{1}} & 0 & 0 \\
0 & \frac{1-D_{0}}{A_{L} N_{22} C_{2}} & 0 & -\frac{1}{C_{2} R}
\end{array}\right]
$$




$$
B=\left[\begin{array}{cc}
\frac{D_{0}}{N_{11}+N_{12}} & \frac{U_{C 10} N_{11}+N_{12} U_{10}}{\left(N_{11}+N_{12}\right) N_{12}} \\
0 & \left(\frac{U_{C 10}}{N_{21}}+\frac{U_{C 20}}{N_{22}}\right) \\
0 & \frac{N_{11} N_{21} \Phi_{10}-\Phi_{20}\left(N_{11}+N_{12}\right) N_{12}}{A_{L}\left(N_{11}+N_{12}\right) N_{12} N_{21} C_{1}} \\
0 & -\frac{\Phi_{20}}{A_{L} N_{22} C_{2}}
\end{array}\right]
$$

\subsection{Working point values}

Also the connections of the working point values result from the linearization process. From the first line of (34) one gets

$$
-\left(\frac{D_{0}}{N_{11}+N_{12}}+\frac{1-D_{0}}{N_{12}}\right) U_{C 10}+\frac{D_{0}}{N_{11}+N_{12}} U_{10}=0 .
$$

From this equation one gets again (3). The second line leads to

$$
\frac{D_{0}}{N_{21}} U_{C 10}=\frac{1-D_{0}}{N_{22}} U_{C 20} .
$$

By easy calculation we get again (4).

From

$$
\left(\frac{D_{0}}{A_{L}\left(N_{11}+N_{12}\right) C_{1}}+\frac{1-D_{0}}{A_{L} N_{12} C_{1}}\right) \Phi_{10}-\frac{D_{0}}{A_{L} N_{21} C_{1}} \Phi_{20}=0
$$

With the working point flux of the flyback transformer $\Phi_{20}$ one gets for the flux at the working point in the first coupled coils $\Phi_{10}$

$$
\Phi_{10}=\frac{N_{11}+N_{12}}{N_{11}+N_{12}-D_{0} N_{11}} \frac{D_{0}}{N_{21}} \Phi_{20} .
$$

From the last line of (34) we get the working point connection of the flux in the flyback transformer with the load current

$$
\frac{1-D_{0}}{A_{L} N_{22}} \Phi_{20}=\frac{U_{C 20}}{R}=I_{L O A D} .
$$

\subsection{Transfer function}

The linear model can be used to calculate the transfer functions. These are useful for designing the controller, for drawing Bode plots and for doing simulations. The state-space description combines the differential equations into one matrix system. With the help of the Laplace transformation this system can be transformed into the frequency domain (s-domain). This leads to a linear equation system of forth order. Using Crammer's algorithm and the determinant calculus, the transfer function can be calculated (another way is to construct a signal flow graph and apply Mason's rule). Starting from the common form

$$
\begin{aligned}
\frac{d}{d t}\left(\begin{array}{l}
\hat{\phi}_{1} \\
\hat{\phi}_{2} \\
\hat{u}_{C 1} \\
\hat{u}_{C 2}
\end{array}\right) & =\left[\begin{array}{cccc}
0 & 0 & A_{13} & 0 \\
0 & 0 & A_{23} & A_{24} \\
A_{31} & A_{32} & 0 & 0 \\
0 & A_{42} & 0 & A_{44}
\end{array}\right]\left(\begin{array}{l}
\hat{\phi}_{1} \\
\hat{\phi}_{2} \\
\hat{u}_{C 1} \\
\hat{u}_{C 2}
\end{array}\right) \\
& +\left[\begin{array}{cc}
B_{11} & B_{12} \\
0 & B_{22} \\
0 & B_{32} \\
0 & B_{42}
\end{array}\right]\left(\begin{array}{c}
\hat{u}_{1} \\
\hat{d}
\end{array}\right)
\end{aligned}
$$

one gets for the denominator of the transfer functions

$$
\begin{aligned}
N= & s^{4}-A_{44} \cdot s^{3}-\left(A_{13} A_{31}+A_{23} A_{32}+A_{24} A_{42}\right) \cdot s^{2}+ \\
& +\left(A_{13} A_{31} A_{44}+A_{23} A_{32} A_{44}\right) \cdot s+A_{13} A_{24} A_{31} A_{42}= \\
& =s^{4}+a_{3} s^{3}+a_{2} s^{2}+a_{1} s+a_{0}
\end{aligned}
$$

The numerator for the transfer function $\mathrm{U}_{\mathrm{C}_{2}} / \mathrm{D}$ for the control signal can be written as (using Crammer's law)

$$
\begin{aligned}
Z_{D}= & B_{42} s^{3}+A_{42} B_{22} \cdot s^{2}+\left[\begin{array}{l}
A_{23} A_{42} B_{32} \\
-\left(A_{13} A_{31}+A_{23} A_{32}\right) B_{42}
\end{array}\right] \cdot s \\
& +\left(A_{23} A_{31} B_{12}-A_{13} A_{31} B_{22}\right) A_{42} \\
= & b_{3} s^{3}+b_{2} s^{2}+b_{1} s+b_{0} .
\end{aligned}
$$

The numerator of the disturbance output transfer function $\mathrm{U}_{\mathrm{C} 2} / \mathrm{U}_{1}$ is given by

$$
Z_{U 1}=A_{23} A_{31} A_{42} B_{11}=c_{0} .
$$

The transfer function between the output voltage $\mathrm{U}_{2}(\mathrm{~s})$ and the control signal $\mathrm{D}(\mathrm{s})$ can be written according to

$$
G_{U 2 D}(s)=\frac{U_{2}(s)}{D(s)}=\frac{b_{3} s^{3}+b_{2} s^{2}+b_{1} s+b_{0}}{s^{4}+a_{3} s^{3}+a_{2} s^{2}+a_{1} s+a_{0}} .
$$

For the influence of the disturbance (changes of the input voltage) one gets the transfer function

$$
G_{U 2 U 1}(s)=\frac{U_{2}(s)}{U_{1}(s)}=\frac{c_{0}}{s^{4}+a_{3} s^{3}+a_{2} s^{2}+a_{1} s+a_{0}} .
$$

\section{Dimensioning}

\subsection{Dimensioning of the output capacitor C2}

During the on-time of the active switch S, the capacitor has to supply the load. Choosing a voltage ripple $\Delta \mathrm{u}_{\mathrm{C} 2}$, the voltage decreases during M1 according to

$$
\Delta u_{C 2}=\frac{1}{C_{2}} \int_{0}^{d T} I_{\text {Load }} d t .
$$

Solving and rearranging leads to

$$
C_{2}=\frac{1}{\Delta u_{C 2}} \cdot \frac{I_{\text {Load }} d}{f} \text {. }
$$


The equivalent series resistor of the capacitor causes a higher capacitor value.

\subsection{Dimensioning of the coupled inductors $\mathrm{N}_{11} \& \mathrm{~N}_{12}$}

With a chosen current ripple $\Delta \mathrm{I}_{\mathrm{L}}$ when both windings are working in series, one gets for the inductor

$$
\left(N_{11}+N_{12}\right)^{2} A_{L}=L=\frac{\left(U_{1}-U_{C 1}\right) d}{\Delta I_{L} f}
$$

When a bifilar winding is chosen, one has to split the complete winding into two halves. Details how to dimension the necessary air gap are similar to the described procedure for the flyback transformer.

\subsection{Dimensioning of the fly-back transformer}

For the primary winding one can calculate using the on-time of the active switch and a chosen current ripple $\Delta \mathrm{I}_{\mathrm{LN} 21}$

$$
L_{N 21}=\frac{U_{C 1} d}{\Delta I_{L N 21} f} .
$$

The energy, which is stored in the magnetic core, consists of the energy in the ferrite material and in the air gap. From the theory of magnetics one knows the equation for the energy density

$$
\frac{B H}{2}=\frac{W_{M a g}}{V} .
$$

This leads for the magnetic circuit with an airgap to

$$
\frac{B^{2}}{\mu_{0} \mu_{r}} V_{F e}+\frac{B^{2}}{\mu_{0}} V_{A i r}=\frac{L I^{2}}{2} \text {. }
$$

Due to the fact that the relative permeability $\mu_{\mathrm{r}}$ of ferrite is much higher than that of the air which is only one, one can see that the energy is primarily stored in the air gap! One can now write approximately for the air gap volume $\mathrm{V}_{\text {Air }}$ and the air gap length $1_{\text {Air }}$

$$
V_{A i r} \approx \frac{L I^{2} \mu_{0}}{B^{2}}=l_{A i r} A_{F e} .
$$

For a given core with a cross section of $\mathrm{A}_{\mathrm{Fe}}$, a maximal allowable flux density $\mathrm{B}$ and a peak current I the necessary air gap can be calculated according to

$$
l_{A i r}=\frac{L \hat{I}^{2} \mu_{0}}{A_{F e} \hat{B}^{2}} .
$$

The so-called $\mathrm{A}_{\mathrm{L}}$-value for the chosen core depends on the air gap and can be found in the data sheet. The value of the inductor depends on this $A_{L}$-value multiplied by the square of the turns

$$
N_{21}=\sqrt{\frac{L_{N 21}}{A_{L}}}
$$

The inductance of the secondary winding can now be calculated with the help of

$$
L_{N 22}=A_{L} N_{22}^{2}
$$

\section{Simulation}

To get a better comprehension of the circuit, simulations with LT-Spice were done. The current through the load, the input voltage, the voltage across the capacitor $\mathrm{C}_{1}$, and the output voltage are shown up to down in Fig. 10. To avoid overload of the currents and voltages, the converter is started with increasing duty cycle as done during soft-start of a real converter. The duty cycle increases within the first $15 \mathrm{~ms}$. The voltage across the capacitor $\mathrm{C}_{1}$ and the output voltage increase therefore continuously without significant overshot. After the soft-start has finished, the stationary case is reached within two milliseconds. At $20 \mathrm{~ms}$ an input voltage step occurs. Within three milliseconds a new steadystate case is reached. After $25 \mathrm{~ms}$ a load step occurs. The load is increased and the load current is now nearly double as the original value. Within $3 \mathrm{~ms}$ the new steady-state case is reached. At $30 \mathrm{~ms}$ the duty cycle is decreased and therefore the output voltage and the load current decrease, too.

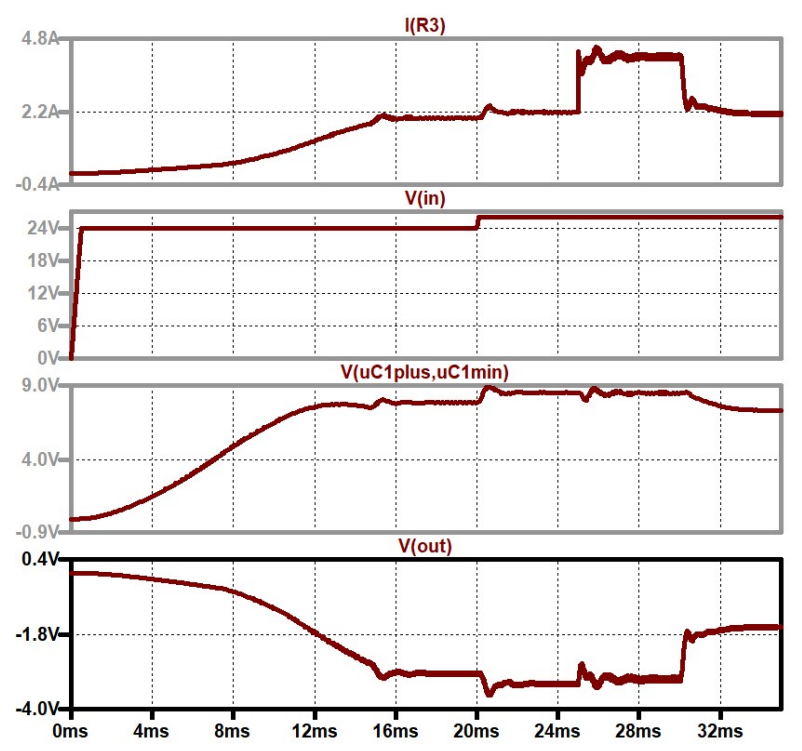

Fig. 10. Up to down: load current, duty cycle, input voltage, voltage across $\mathrm{C} 1$, output voltage.

The voltage at the output increases linearly within the first $8 \mathrm{~ms}$ because the converter is there in the discontinuous mode. Then it increases quadratically, because the converter is now in the continuous mode. Fig. 11 shows the currents through the 
coupled windings in a steady-state case. The winding ratio of the flyback transformer is $\mathrm{N}_{21}: \mathrm{N}_{22}=2: 1$, the winding ratio of the tapped inductor is $\mathrm{N}_{11}: \mathrm{N}_{12}=1: 1$. The step in the currents can be seen clearly. The plots show up to down: the control signal of the active switch, the current through the secondary winding of the flyback transformer, the current through the primary winding of the transformer, the current through the second half, and the current through the first half of the tapped inductor. For the model converter the capacitors were chosen to $330 \mu \mathrm{F}$, the inductivity of the windings of the tapped inductor are $40 \mu \mathrm{H}$, the primary inductor and the secondary inductor of the flyback transformer were chosen to $33 \mu \mathrm{H}$ and $8 \mu \mathrm{H}$, respectively.

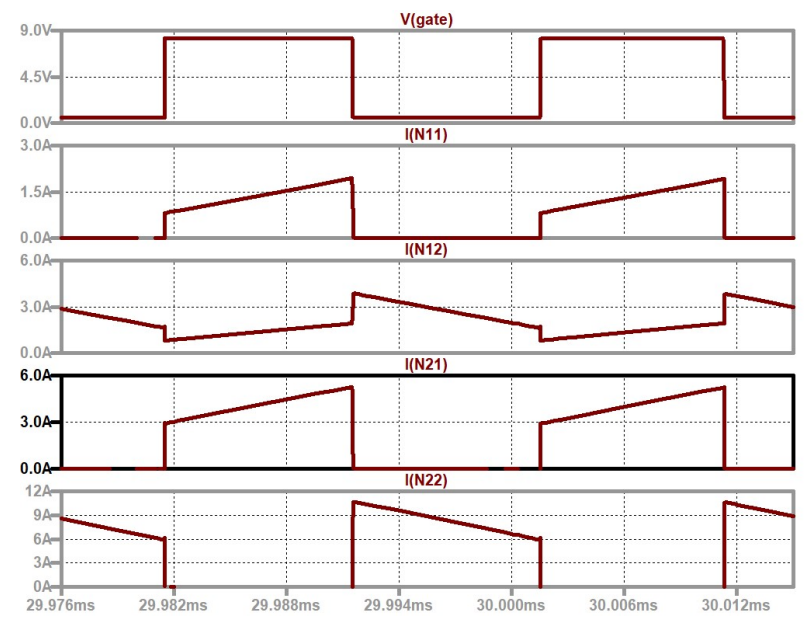

Fig. 11. (up to down): gate signal, current through the secondary winding of the flyback transformer, current through the primary winding of the flyback transformer, current through second half of the tapped inductor, and current through first half of the tapped inductor.

\section{Conclusions}

A flyback converter with a quadratic input stage realized with a tapped inductor (or autotransformer) was analyzed and material for the design was given. The coupling between the windings of the tapped inductor and of the flyback transformer should be strong. When higher winding ratios are necessary, the stray inductance is higher and a recuperative snubber or an overvoltage limiter with the possibility to feed back the energy stored in the stray inductances should be used. Due to the coupled inductors and the quadratic term in the voltage transformation ratio, the converter can be fitted for complex applications. The converter has, because of the winding ratios, additional degrees of freedom in the design and can be adapted to a wide voltage range. Only one active switch is necessary and has to be controlled. The circuit is useful for a power range of up to a few hundred watts.

\section{References:}

[1] F. Zach, Power Electronics, in German: Leistungselektronik, Wien: Springer, 5th ed., 2016.

[2] N. Mohan, T. Undeland and W. Robbins, Power Electronics, Converters, Applications and Design, 3nd ed. New York: W. P. John Wiley \& Sons, 2003.

[3] Y. Rozanov, S. Ryvkin, E. Chaplygin, P. Voronin, Power Electronics Basics, CRC Press, 2016.

[4] D. Maksimovic, and S. Cuk, Switching converters with wide DC conversion range, IEEE Transactions on Power Electronics, vol. 6, January 1991, pp. $151-157$.

[5] F. A. Himmelstoss, and H. Votzi: A family of quadratic DC/DC converters with one low-side switch and a tapped inductor at the output side, Proceedings of $O P T I M \& A C E M P$, Istanbul Aug. 2019.

[6] F. A. Himmelstoss and H. L. Votzi, Four quadratic DC/DC converters with one low-side switch and a tapped inductor at the input side, IECON 2019, Lisbon, Portugal, 2019, pp. 17741779.

[7] D. S Wijeratne, and G. Moschopoulos, Quadratic Power Conversion for Power Electronics: Principles and Circuits, IEEE Transactions on Circuits and Systems I, vol. 59, Feb. 2012, pp. $426-438$.

[8] K. Pirghaibi and F. A. Himmelstoss: A stepdown converter with high down-scale ratio, Proceedings of OPTIM \& ACEMP, 2017, Brasov, pp. 567-572.

[9] A. Ayachit, M. K. Kazimierczuk, Open-loop small-signal transfer functions of the quadratic buck PWM DC-DC converter in CCM, 40th Annual Conf. of the IEEE Industr. Electronics Society, IECON 2014, pp. 1643-1649.

[10] L dos Reis Barbosa, J. B. Vieira Jr.; L.C. de Freitas, M. da Silva Vilela, V. J. Farias,. A buck quadratic PWM soft-switching converter using a single active switch, IEEE Tr. on Power Electronics, Vol. 14, Issue: 3, pp. 445 - 453.

[11]H. Cheng, H., K. M. Smedley, A. Abramovitz, A Wide-Input-Wide-Output (WIWO) DC-DC Converter", IEEE Tr. on Power Electronics, Vol: 25, Issue: 2, Feb. 2010, pp. $280-289$.

[12] D. S. Wijeratne, G. Moschopoulos, Quadratic Power Conversion for Power Electronics:, IEEE Tr. on Circuits and Systems I: Regular Papers, Volume: 59, Issue: 2, Feb. 2012pp. $426-438$. 